\title{
Динаміка показників рівня розвитку сили школярів старших класів під впливом вправ кросфіту
}

\section{Ангеліна Петрова Тетяна Бала}

\author{
Харківська державна академія фізичної культури, Харків, Україна
}

Мета: визначити вплив занять кросфітом на прояв силових здібностей дітей старшого шкільного віку.

Матеріал і методи: теоретичний аналіз наукової та методичної літератури; тестування, експеримент (педагогічний) та методи математичної статистики. Для визначення досліджуваних параметрів учнів старших класів використовувалися такі тести: піднімання прямих ніг у висі (кількість разів); згинання та розгинання рук в упорі лежачи на підлозі (кількість разів); потрійний стрибок на правій і лівій нозі (м). Отримані результати порівнювалися з нормативними оцінками й оцінювалися за певною кількістю балів. Статистичний аналіз: матеріали дослідження оброблялися з використанням ліцензованої програми Ехcеl. У дослідженні взяли участь 113 школярів 10-11-х класів.

Результати: на початку навчального року нами було проведено констатувальний експеримент, за результатами якого встановлено нижчий за середній рівень розвитку силових здібностей у школярів старшої школи. Для подальшого проведення формувального експерименту учнів було розподілено на основні та контрольні групи. Учні контрольних груп займалися за загальноприйнятою державною програмою з фізичної культури, а освітній процес з фізичного виховання школярів основних груп був доповнений розробленим нами варіативним модулем «Кросфіт». За результатами досліджень, які отримані після впровадження в освітній процес з фізичного виховання експериментальної методики, визначено, що у школярів основних груп рівень розвитку силових здібностей підвищився з нижче середнього до вище середнього. У досліджуваних контрольних групах не виявлено змін за оціночною шкалою. За віком спостерігається, в основному, покращення результатів у школярів обох досліджуваних груп (p>0,05). За статтю виявлено, переважно, достовірне превалювання даних юнаків над показниками дівчат $(p<0,05-0,001)$.

Висновки: виявлено значні позитивні зміни у показниках рівня розвитку сили учнів 10-11-х класів основних груп після застосування в освітній процес з фізичного виховання запропонованої нами експериментальної методики.

Ключові слова: варіативний модуль, кросфіт, учні старших класів, сила, уроки фізичної культури, рухова активність.

\section{Вступ}

Проблема погіршення стану здоров'я та зниження рівня рухової підготовленості учнівської молоді опинилась на ряду пріоритетних проблем національного рівня [8]. Чисельними дослідженнями [1; 2; 4; 20] визначено, що найчастіше причиною різних відхилень у стані здоров'я дітей та підлітків $€$ недостатня рухова активність, яка прогресує з кожним роком. Тому на сьогодні найактуальнішим завданням нашої держави є збільшення рухової активності школярів, як фундаменту для збереження здоров'я та підвищення рівня фізичної підготовленості [15].

Науковими дослідженнями [3; 5; 14; 22] доведено, що заняття фізичною культурою та спортом сприяють поліпшенню фізичного та функціонального стану організму дітей різного шкільного віку. Однак, згідно даних низки фахівців [1; 6; 8; 9], визначено, що сучасний урок фізичної культури не тільки не компенсує дефіцит рухової активності, а і є недостатньо ефективним для учнів різного шкільного віку. Основними причинами зазначеної проблеми є одноманітність навчального матеріалу, зниження інтересу учнів до фізкультурно-спортивної діяльності, недостатня інформованість та обмеженість у доступі вчителів до сучасних тенденцій фізкультурної освіти $[1 ; 9 ; 10]$. Саме тому пріоритетним питанням сьогодення залишається модернізація освітнього процесу фізичного виховання, за рахунок включення інноваційних видів спорту в систему шкільної фізичної освіти.

Низка провідних фахівців галузі фізичної культури та спорту займались проблематикою вдосконалення навчального процесу з фізичного виховання шляхом впровадження нових, інноваційних видів рухової активності, в результаті яких спостерігається підвищення рівня фізичної підготовленості учнів, зокрема й розвитку силових здібностей $[1 ; 2 ; 4 ; 8 ; 10 ; 13]$. Відомо, що сила $€$ інтегральною руховою якістю, від якої, тою чи іншою мірою, залежить прояв усіх інших рухових здібностей, що свідчить про велике значення цілеспрямованого її виховання [17]. Особливу увагу в цьому аспекті слід приділяти дітям старшого шкільного віку, оскільки сенситивний період розвитку сили припадає на вік 15-18-ти років. У даному віці інтенсивне зростання силових показників 


\section{СЛОБОЖАНСЬКИЙ НАУКОВО-СПОРТИВНИЙ ВІСНИК}

можна пояснити збільшенням м'язової маси, статевим дозріванням, підвищенням швидкості скорочення м'язів до тривалої напруги статичного характеру [18].

Чисельними дослідженнями провідних фахівців доведено покращення рівня розвитку сили під впливом занять різними видами рухової діяльності. Так, науковці Т. М. Кравчук, Т. В. Карпунець, І. В. Степаненко [5] вказують, що впровадження в основну частину уроку функціональних вправ сприяло значному покращенню силових здібностей старшокласників; Т. І. Суворова, М. С. Мороз, А. Г. Карабанов [14], зазначають, що під впливом занять атлетичною гімнастикою суттєво поліпшився рівень розвитку сили у школярів старших класів; Л. Горбунов [3], свідчить, що у юнаків та дівчат 10-х класів простежується тенденція до покращення рівня розвитку сили під впливом оздоровчого туризму; І. М. Скрипка, С. В. Черідніченко, М. О. Лисяк [13] виявили позитивну динаміку рівня розвитку силових можливостей у юнаків 16-17-ти років після впровадження в навчальний процес розробленої програми силового спрямування. Слід зазначити, що в доступній нам науково-методичній літературі не виявлено наукових робіт, які б порушували питання стосовно впливу вправ кросфіту на показники рівня розвитку сили учнів старшої школи, що і обґрунтувало доцільність проведення нашого дослідження.

В Україні кросфіт з кожним днем набуває великої популярності серед людей різного віку, зокрема й учнівської молоді. Його унікальність полягає у варіативності, широкому спектрі впливу на основні системи організму, поєднанні вправ з різних видів спорту [19; 21; 23; 24].

Таким чином, ми вважаємо, що застосування саме кросфіту в освітній процес з фізичного виховання $є$ доцільним та своєчасним, оскільки він дозволить оптимізувати зміст уроку фізичної культури, зробить його більш сучасним, цікавим та ефективним.

Мета дослідження - визначити вплив занять кросфітом на прояв силових здібностей дітей старшого шкільного віку.

Зв'язок роботи із науковими програмами, планами, темами. Дослідження проводилося відповідно до Тематичного плану науково-дослідної роботи Харківської державної академії фізичної культури на 2015-2020 рр. за темою «Вдосконалення процесу фізичного виховання в навчальних закладах різного профілю» (номер державної реєстрації 0115U006754) та на 2020-2026 рр. за темою «Вдосконалення процесу фізичного виховання різних верств населення» (номер державної реєстрації 0120U101110).

\section{Матеріал і методи дослідження}

У ході експерименту використовувались наступні методи: теоретичний аналіз наукової та методичної літератури з даної проблематики; тестування, експеримент (педагогічний) та методи математичної статистики.

Рівень розвитку сили учнів 10-11-х класів визначався за допомогою тестів, запропонованих Л. П. Сергієнком [12] та В. А. Романенком [11], а саме: піднімання прямих ніг у висі (кількість разів); згинання та розгинання рук в упорі лежачи на підлозі (кількість разів); потрійний стрибок на правій і лівій нозі (м).

Статистичний аналіз: матеріали дослідження оброблялися з використанням ліцензованої програми Excel. Обчислювалися: середнє арифметичне варіаційного ряду ( ); похибка репрезентативності (m) та достовірність відмінностей (р) з метою встановлення однорідності контрольних та основних груп, ступеню відмінностей показників у віковому аспекті та зміни середніх величин досліджуваних параметрів після проведення експерименту за допомогою параметричного критерію Стьюдента (t) при рівні значущості не нижче 0,05.

Дослідження проводилось на базі загальноосвітніх шкіл № 146 та № 57 м. Харкова впродовж навчального року. В ньому брало участь 113 школярів 16-17-ти років, з яких було сформовано 2 основні та 2 контрольні групи. Основні групи включали 59 школярів: перша група - хлопці та дівчата 16 років ( $n=27)$, друга група - хлопці та дівчата 17 років $(\mathrm{n=32})$; контрольні групи включали 54 школярів: перша група - хлопці та дівчата 16 років $(n=21)$ та друга група - хлопці та дівчата 17 років $(n=33)$. Всі діти, які приймали участь у дослідженні, відносилися до основної та підготовчої медичної групи, були практично здорові та знаходилися під наглядом шкільного лікаря. Від батьків усіх учнів було отримано згоду на участь у педагогічному експерименті.

В ході дослідження школярі контрольних груп займалися за загальноприйнятою державною програмою з фізичної культури, а навчальний процес з фізичного виховання школярів основних груп був доповнений розробленим нами варіативним модулем «Кросфіт». Заняття з кросфіту проводилися два рази на тиждень. До змісту якого входили теоретичні відомості, спеціальна фізична підготовка (елементи гімнастики, легкої та важкої атлетики, гирьовий спорт, загальнорозвивальні вправи) та технічна підготовка (спеціально підібрані вправи кросфіту «Burpee», «Box Jump», «Farmer's Walk», «Burpee bench jump» тощо). Після освоєння модуля «Кросфіт» учні виконували комплекс вправ у полегшених умовах, який складався зі спеціальних та технічних елементів кросфіту у різних режимах роботи (EMOM, AMRAP, AFAP, Tabata, Chipper) та із зазначеною кількістю раундів [16].

\section{Результати дослідження}

Розглядаючи показники рівня розвитку сили, отримані в результаті проведення констатувального експерименту (табл. 1), виявлено відсутність достовірних відмінностей між результатами досліджуваних груп за усіма параметрами $(p>0,05)$

У віковому аспекті встановлено покращення даних 3 віком у школярів обох досліджуваних груп, однак, ці розрізнення носять недостовірний характер $(p>0,05)$. Слід зазначити, що достовірний характер відмінностей спостерігається лише за результатами потрійного стрибка на правій і лівій нозі у дівчат контрольних груп $(p<0,001)$. Порівнюючи показники за статтю, виявлено, в основному, достовірне превалювання даних юнаків над результатами дівчат ( $p<0,05-0,001)$.

Визначаючи загальний рівень розвитку силових здібностей до проведення педагогічного експерименту, встановлено, що у школярів 10-11-х класів обох груп результати відповідають нижче середньому рівню.

Після застосування варіативного модуля «Кросфіт» в освітній процес з фізичного виховання виявлено суттєве покращення за всіма досліджуваними параметрами, як у хлопців, так і у дівчат основних груп, і ці розрізнення носять достовірний характер ( $p<0,05-0,001)$. Так, приріст результатів, що відображають рівень розвитку 
Таблиця 1

Порівняння показників розвитку силових здібностей учнів основних і контрольних груп до експерименту

\begin{tabular}{|c|c|c|c|c|c|c|c|}
\hline \multirow{3}{*}{ Класи } & & \multicolumn{4}{|c|}{ Групи } & \multirow{3}{*}{$\mathrm{t}$} & \multirow{3}{*}{$\mathrm{p}$} \\
\hline & \multirow{2}{*}{ Стать } & $\mathrm{n}$ & Основні групи & $\mathrm{n}$ & Контрольні групи & & \\
\hline & & \multicolumn{4}{|c|}{ Показники $\bar{X} \pm \mathrm{m}$} & & \\
\hline \multicolumn{8}{|c|}{ Піднімання прямих ніг у висі (кількість разів) } \\
\hline \multirow{2}{*}{$\begin{array}{c}10 \\
\text { клас }\end{array}$} & Хлопці & 17 & $14,35 \pm 1,74$ & 10 & $12,90 \pm 1,26$ & 0,68 & $>0,05$ \\
\hline & Дівчата & 12 & $7,83 \pm 1,93$ & 11 & $7,27 \pm 1,44$ & 0,23 & $>0,05$ \\
\hline \multirow{2}{*}{$\begin{array}{c}11 \\
\text { клас }\end{array}$} & Хлопці & 10 & $16,00 \pm 2,35$ & 17 & $14,76 \pm 0,83$ & 0,50 & $>0,05$ \\
\hline & Дівчата & 22 & $9,86 \pm 0,99$ & 16 & $9,31 \pm 1,41$ & 0,32 & $>0,05$ \\
\hline \multicolumn{8}{|c|}{ Згинання та розгинання рук в упорі лежачи (кількість разів) } \\
\hline \multirow{2}{*}{$\begin{array}{c}10 \\
\text { клас }\end{array}$} & Хлопці & 17 & $27,47 \pm 2,10$ & 10 & $27,60 \pm 3,82$ & 0,03 & $>0,05$ \\
\hline & Дівчата & 12 & $8,50 \pm 1,68$ & 11 & $9,82 \pm 1,35$ & 0,61 & $>0,05$ \\
\hline \multirow{2}{*}{$\begin{array}{c}11 \\
\text { клас }\end{array}$} & Хлопці & 10 & $30,70 \pm 2,54$ & 17 & $31,76 \pm 2,46$ & 0,30 & $>0,05$ \\
\hline & Дівчата & 22 & $11,50 \pm 1,28$ & 16 & $12,06 \pm 0,99$ & 0,35 & $>0,05$ \\
\hline \multicolumn{8}{|c|}{ Потрійний стрибок на правій і лівій нозі (см) } \\
\hline \multirow{2}{*}{$\begin{array}{c}10 \\
\text { клас }\end{array}$} & Хлопці & 17 & $5,63 \pm 0,15$ & 10 & $5,33 \pm 0,30$ & 0,89 & $>0,05$ \\
\hline & Дівчата & 12 & $3,94 \pm 0,17$ & 11 & $3,65 \pm 0,17$ & 1,24 & $>0,05$ \\
\hline \multirow{2}{*}{$\begin{array}{c}11 \\
\text { клас }\end{array}$} & Хлопці & 10 & $5,71 \pm 0,21$ & 17 & $5,64 \pm 0,20$ & 0,25 & $>0,05$ \\
\hline & Дівчата & 22 & $4,96 \pm 1,13$ & 16 & $4,94 \pm 0,18$ & 0,02 & $>0,05$ \\
\hline
\end{tabular}

максимальної динамічної сили м'язів черевного пресу у юнаків 10-го класу склав - 24,5\%, 11-го класу - 23,7\%; у дівчат відповідно - 55,3\% та 43,3\%; максимальної сили - у юнаків 10-го класу становить 27,8\%, 11-го класу 17,9\%; у дівчат відповідно 44,1\% та 30,8\%; швидкісної сили - у юнаків 10-го класу становить 6,6\%, 11-го класу - 9,4\%; у дівчат відповідно 20,5\% та 46,7\%.
Аналіз вторинних даних за віком та статтю у школярів основних груп встановив, що. в основному, тенденція розрізнень залишилася незмінною в порівнянні з вихідними результатами.

Досліджуючи показники учнів контрольних груп після експерименту, встановлено, що вони також дещо покращилися, однак, ці зміни не суттєві та не достовірні

Таблиця 2

Порівняння показників розвитку силових здібностей учнів основних і контрольних груп після експерименту

\begin{tabular}{|c|c|c|c|c|c|c|c|}
\hline \multirow{3}{*}{ Класи } & \multirow{3}{*}{ Стат } & \multicolumn{4}{|c|}{ Групи } & \multirow{3}{*}{$\mathrm{t}$} & \multirow{3}{*}{$\mathrm{p}$} \\
\hline & & $\mathrm{n}$ & Основні & $\mathrm{n}$ & Контрольні & & \\
\hline & & \multicolumn{4}{|c|}{ Показники $\bar{X} \pm \mathrm{m}$} & & \\
\hline \multicolumn{8}{|c|}{ Піднімання прямих ніг у висі (кількість разів) } \\
\hline \multirow{2}{*}{10 клас } & Хлопці & 17 & $17,88 \pm 2,11$ & 10 & $13,70 \pm 1,34$ & 1,67 & $>0,05$ \\
\hline & Дівчата & 12 & $12,17 \pm 2,06$ & 11 & $7,91 \pm 1,31$ & 1,74 & $>0,05$ \\
\hline \multirow{2}{*}{11 клас } & Хлопці & 10 & $19,80 \pm 1,53$ & 17 & $15,12 \pm 0,86$ & 2,67 & $<0,05$ \\
\hline & Дівчата & 22 & $14,14 \pm 0,93$ & 16 & $10,19 \pm 1,25$ & 2,54 & $<0,05$ \\
\hline \multicolumn{8}{|c|}{ Згинання та розгинання рук в упорі лежсачи (кількість разів) } \\
\hline \multirow{2}{*}{10 клас } & Хлопці & 17 & $35,12 \pm 1,56$ & 10 & $27,80 \pm 3,78$ & 1,79 & $>0,05$ \\
\hline & Дівчата & 12 & $12,25 \pm 1,69$ & 11 & $10,82 \pm 1,45$ & 0,64 & $>0,05$ \\
\hline \multirow{2}{*}{11 клас } & Хлопці & 10 & $36,20 \pm 2,00$ & 17 & $32,94 \pm 2,54$ & 1,01 & $>0,05$ \\
\hline & Дівчата & 22 & $15,05 \pm 1,20$ & 16 & $12,38 \pm 1,00$ & 1,71 & $>0,05$ \\
\hline \multicolumn{8}{|c|}{ Потрійний стрибок на правій і лівій нозі (см) } \\
\hline \multirow{2}{*}{10 клас } & Хлопці & 17 & $6,01 \pm 0,13$ & 10 & $5,42 \pm 0,29$ & 1,83 & $>0,05$ \\
\hline & Дівчата & 12 & $4,75 \pm 0,18$ & 11 & $3,79 \pm 0,20$ & 3,62 & $<0,01$ \\
\hline \multirow{2}{*}{11 клас } & Хлопці & 10 & $6,25 \pm 0,18$ & 17 & $5,65 \pm 0,20$ & 2,20 & $<0,05$ \\
\hline & Дівчата & 22 & $7,27 \pm 0,16$ & 16 & $4,97 \pm 0,17$ & 9,74 & $<0,001$ \\
\hline
\end{tabular}




\section{СЛОБОЖАНСЬКИЙ НАУКОВО-СПОРТИВНИЙ ВІСНИК}

( $>0,05)$. Так, приріст результатів варіював в межах від 0,3\% до 10,1\%. Слід зазначити, що за віком та статтю не виявлено змін у порівнянні з початковими даними.

Порівнюючи отримані дані школярів основних і контрольних груп (табл. 2) після впровадження вправ кросфіту, нами було встановлено, що результати учнів основних груп кращі за показники школярів контрольних груп. Слід зазначити, що достовірний характер відмінностей простежується за показниками піднімання прямих ніг у висі школярів 11-го класу $(p<0,05)$; потрійного стрибка на правій і лівій нозі у дівчат 10-го класу $(p<0,01)$ та школярів 11-го класу ( $<<0,05 ; 0,001)$.

Встановлюючи загальний рівень розвитку силових здібностей після застосування варіативного модуля «Кросфіт» в систему шкільної фізичної освіти, визначено, що у школярів 10-11-х класів основних груп дані покращились 3 нижче середнього рівня до вище середнього. Слід зазначити, що показники учнів контрольних груп суттєво не змінились та відповідають, як і на початку дослідження, нижче середньому рівню.

Тому вищезазначене свідчить, що впровадження вправ кросфіту в освітній процес з фізичного виховання позитивно вплинуло на рівень розвитку сили учнів старшого шкільного віку основних груп.

\section{Висновки / Дискусія}

Згідно з результатами досліджень встановлено, що після впровадження в освітній процес з фізичного виховання експериментальної програми спостерігається суттєве покращення рівня розвитку силових здібностей учнів старшої школи. Так, достовірні зміни простежуються за усіма досліджуваними параметрами, як у хлопців, так і у дівчат основних груп ( $p<0,05 ; 0,001)$.

Отримані нами результати узгоджуються 3 даними Г. М. Шамардіної (2007), Б. М. Шияна (2009), Ю. Ф. Курамшина (2010), які свідчать, що найбільш високі темпи приросту абсолютної сили за показниками дев'яти основних груп м'язів відзначаються у юнаків з 13-14-ти та 16-18-ти років, у дівчат з 10-11-ти та 16-17-ти років. Відносні показники сили особливо значними темпами збільшуються у дітей 9-11-ти та 16-17-ти років.

Доповнено дані чисельними працями провідних фахівців, згідно з якими спостерігається покращення рівня розвитку сили у дітей старшої школи під впливом занять різними видами рухової діяльності. Так, науковці Т. М. Кравчук, Т. В. Карпунець, І. В. Степаненко (2019), вказують, що впровадження в основну частину уроку функціональних вправ сприяло значному покращенню силових здібностей старшокласників; Т. І. Суворова, М. С. Мороз, А. Г. Карабанов (2011) зазначають, що під впливом занять атлетичною гімнастикою суттєво поліпшився рівень розвитку сили у школярів старших класів; Л. Горбунов (2016) свідчить, що у юнаків та дівчат 10-х класів простежується тенденція до покращення рівня розвитку сили під впливом оздоровчого туризму; І. М. Скрипка, С. В. Черідніченко, М. О. Лисяк (2018) виявили позитивну динаміку рівня розвитку силових можливостей у юнаків 16-17-ти років після впровадження в навчальний процес розробленої програми силового спрямування.

Розглядаючи показники рівня розвитку сили школярів контрольних груп, отримані після експерименту, визначено, що вони також дещо покращились, але ці зміни менш суттєві, ніж у досліджуваних експериментальних групах і недостовірні ( $p>0,05)$.

Отже, проведені нами дослідження свідчать про позитивний вплив запропонованих нами вправ кросфіту на рівень розвитку силових здібностей школярів 10-11х класів, що дає можливість рекомендувати вчителям фізичної культури вносити в навчальний процес з фізичного виховання школярів старших класів розроблений нами варіативний модуль «Кросфіт».

Перспективи подальших досліджень у даному напрямку можуть здійснюватися шляхом визначення рівня фізичної підготовленості школярів старших класів під впливом вправ кросфіту.

Конфлікт інтересів. Автори заявляють, що відсутній конфлікт інтересів, який може сприйматись таким, що може завдати шкоди неупередженості статті.

Джерела фінансування. Ця стаття не отримала фінансової підтримки від державної, громадської або комерційної організації.

\section{Список посилань}

1. Бала Т. М., Масляк І. П. (2014), «Динаміка показників рівня розвитку бистроти під впливом вправ чирлідингу», Вісник Чернігівського національного педагогічного університету. Сер.: педагогічні науки. Фізичне виховання та спорт, №118 (3), C. 14-17. http://nbuv.gov.ua/UJRN/VchdpuPN_2014_118(3)_5

2. Голенкова Ю. В., Галкіна А. В. (2015), «Розвиток координаційних здібностей дівчат старшого шкільного віку засобами художньої гімнастики», Теорія та методика фізичного виховання, №4, C. 39-44. DOI: 10.17309/tmfv.2015.4.1155.

3. Горбунов Л. (2016), «Вплив оздоровчого туризму на рівень фізичної підготовленості учнів старших класів», Фізичне виховання, спорт і культура здоров'я у сучасному суспільстві: збірник наукових праць, №2 (10), C. 47-49. https://sport.vnu.edu.ua/ index.php/sport/article/view/1098

4. Кравчук Т. М., Голівець К. М. (2015), «Особливості використання танцювальних вправ у фізичному вихованні старшокласниць», Теорія та методика фізичного виховання, №4, C. 11-16. http://nbuv.gov.ua/UJRN/TMFV_2015_4_3

5. Кравчук Т. М., Карпунець Т. В., Степаненко І. В. (2019), «Функціональне тренування як засіб розвитку силових здібностей учнів старших класів», Технології збереження здоров'я, реабілітація і фізична терапія: зб. ст. ХІІ Міжнар. наук. конф., Харків, C. $132-136$.

6. Кренделєва В. У. (2015), «Вплив оздоровчого фітнесу на рівень фізичної підготовленості учнів старших класів», Молодий вчений, №3 (18), С. 175-178.

7. Курамшин Ю. Ф. (2010), Теория и методика физической культуры. Москва: Советский спорт, 320 с.

8. Масляк І. П. (2017), «Вплив аеробіки силової спрямованості на стан кардіореспіраторної системи школярів старших класів», Науковий часопис НПУ імені М. П. Драгоманова, №1 (82), С. 35-38. http://enpuir.npu.edu.ua/handle/123456789/20398 
9. Масляк І. П., Мамешина М. А., Жук В. О. (2014), «Стан використання інноваційних підходів у фізичному вихованні обласних загальноосвітніх навчальних закладів», Слобожанський науково-спортивний вісник, №6 (44), C. 69-72. http://nbuv.gov. ua/UJRN/snsv_2014_6_15

10. Петрова А. С. (2021), «Вплив вправ кросфіту на рівень фізичної під-готовленості школярів старшого шкільного віку», Слобожанський науково-спортивний вісник, №2 (82), C. 63-69. DOI:10.15391/snsv.2021-2.010

11. Романенко В. О. (2005), Диагностика двигательных способностей: учеб. пособие. Донецк: ДонНУ, 290 с.

12. Сергієнко Л.П. (2001), Тестування рухових здібностей школярів. Київ: Олімпійська література, 439 с.

13. Скрипка І. М., Черідніченко С. В., Лисяк М. О. (2018), «Впровадження методики силових тренувань в процес фізичного виховання учнів старших класів», Науковий часопис НПУ імені МП Драгоманова, №6 (100), С. 74-77.

14. Суворова Т. І., Мороз М. С., Карабанов А. Г. (2011), «Вплив занять з атлетичної гімнастики на фізичну підготовленість учнів старших класів», Молодіжний науковий вісник. Розділ 1. Фізична культура, фізичне виховання різних груп населення, №6, C. $13-16$

15. Сулима А. С., Насальський М. Д., Федорчук В. І. (2019), «Вплив секційних занять футболом на фізичну підготовленість школярів 11-12 років», Фізична реабілітація та рекреаційно-оздоровчі технології, №1, С. 20-24.

16. Фізична культура в школі (2019): навчальна програма для 10-11 класів закладів загальної середньої освіти. Київ: Літера лТД, 192 с.

17. Шамардіна Г. М. (2007), Основи теорії та методики фізичного виховання. Дніпропетровськ: Дріант, 486 с.

18. Шиян Б. М. (2009), Теорія і методика фізичного виховання школярів: підручник: у 2-х ч. Тернопіль: Навчальна книгаБогдан, Ч.1, $272 \mathrm{c}$

19. Galimova A., Kudryavtsev M., Galimov G., Osipov A., Astaf'ev N., Zhavner T., et al. (2018), «Increase in power striking characteristics via intensive functional training in CrossFit», Journal of Physical Education and Sport, vol. 18 (2), pp. 585-591. DOI:10.7752/jpes.2018.02085

20. Irina Masliak, Tetiana Bala, Natalia Krivoruchko, Ludmula Shesterova, Irina Kuzmenko, Nina Kulyk, Roman Stasyuk, Vyacheslav Zhuk (2018), «Functional state of cardiovascular system of 10-16-year old teenagers under the influence of cheerleading classe», Journal of Physical Education and Sport, 18 Supplement issue 1, Art 63, pp. 452-458. DOI:10.7752/jpes.2018.s163

21. Kolomiitseva O., Prykhodko I., Prikhodko A., Anatskyi R., Turchynov A., Fushev S., Hunbina S., Garkavyi O. (2020), «Efficiency of Physical Education of University Students Based on the Motivation Choice of the CrossFit Program», Physical Activity Review, Vol. 8, pp. 26-38.

22. Mulyk K. V., Mulyk V. V. (2015), «Motivation of schoolchildren and students for health related tourism», Pedagogics, psychology, medical-biological problems of physical training and sports, №7 (19), pp. 33-38. http://dx.doi.org/10.15561/18189172.2015.0705

23. Sibley B. A. (2012), "Using Sport Education to Implement a CrossFit Unit», Journal of Physical Education, Recreation \& Dance, Vol. 83 (8), pp. 42-48. DOI:10.1080/07303084.2012.10598829

24. Smith M. M., Sommer A. J., Starkoff B. E., Devor S. T. (2013), «Crossfit-based high-intensity power training improves maximal aerobic fitness and body composition», Journal of Strength and Conditioning Research, Vol. 27 (11), pp. 3159-3172. DOI:10.1519/ JSC.0b013e318289e59f

Стаття надійшла до редакції: 16.11 .2021 р.

Опубліковано: 23.12.2021 p.

Аннотация. Ангелина Петрова, Татьяна Бала. Влияние упражений кроссфита на проявление силовых способностей школьников старших классов. Цель: определить влияние занятий кроссфитом на проявление силовых способностей детей старшего школьного возраста. Материал и методы: теоретический анализ и обобщение научно-методической литературы, педагогическое тестирование, педагогический эксперимент и методы математической статистики. Для определения уровня развития силы школьников 10-11-х классов использовались тесты: подъем прямых ног в висе (количество раз); сгибание и разгибание рук в упоре лежа на полу (количество раз); тройной прыжок на правой и левой ноге (м). Изучаемые результаты сравнивались с нормами и оценивались определенным количеством баллов. Статистический анализ: материалы исследования обрабатывались с использованием лицензированной программы ЕхсеІ. В исследовании приняли участие 113 школьников 1011-х классов. Результаты: в начале учебного года нами был проведен констатирующий эксперимент, по результатам которого установлен ниже среднего уровень развития силовых способностей у школьников старшей школы. По результатам первичного исследования учащиеся были распределены на основные и контрольные группы для дальнейшего проведения формирующего эксперимента. Школьники контрольных групп занимались только по общепринятой государственной программе по физической культуре для 10-11 классов заведений общего среднего образования, а образовательный процесс по физическому воспитанию школьников основных групп был дополнен разработанным нами вариативным модулем “Кроссфит». По результатам исследований, полученных после внедрения в образовательный процесс по физическому воспитанию экспериментальной методики определено, что у школьников основных групп, уровень развития силовых способностей повысился с ниже среднего до выше среднего. У исследуемых контрольных групп не обнаружены изменения на оценочной шкале. В возрастном аспекте наблюдается, в основном, улучшение результатов с возрастом, как у школьников основных, так и контрольных групп (p>0,05). В половом аспекте выявлено, в основном, достоверное превалирование данных юношей над показателями девушек ( $<<0,05-$ 0,001). Выводы: выявлены значительные положительные изменения в показателях уровня развития силы учащихся 10-11-х классов основных групп после применения в образовательный процесс по физическому воспитанию предлагаемой нами экспериментальной методики.

Ключевые слова: вариативный модуль, кроссфит, учащиеся старших классов, сила, уроки физической культуры, двигательная активность.

Abstract. Anhelina Petrova, Tetiana Bala. Influence of Crossfit exercises on the power abilities of high school pupils. Purpose: to determine the influence of CrossFit exercises on the power abilities of high school-age children. Materials and methods: theoretical analysis and generalization of scientific and methodological literature, pedagogical testing, pedagogical experiment, and methods of mathematical statistics. Such tests as the lifting of straight legs hanging (number of times); bending and extension of hands lying on the floor (number of times); triple jump on the right and left leg $(\mathrm{m})$ were used to determine the level of the strength development

Петрова, А., Бала, Т. (2021), «Динаміка показників рівня розвитку сили школярів старших класів під впливом вправ кросфіту» doi:10.15391/snsv.2021-6.008 


\section{СЛОБОЖАНСЬКИЙ НАУКОВО-СПОРТИВНИЙ ВІСНИК}

of the 10th-11th-grade pupils. The studied results were compared to norms and evaluated with a certain number of points. Statistical analysis: the research materials were processed using the licensed program Excel. The study involved 113 schoolchildren in grades 10-11. Results: at the beginning of the school year, we conducted the stating experiment, according to the results of which it was established below the average level of development of power abilities in high school pupils. According to the results of the primary research, pupils were assigned to the main and control groups for further conducting the forming experiment. Pupils of control groups were engaged only in the generally accepted state program on physical education for the 10th-11th grades of general secondary education institutions, and the educational process on physical education of pupils of the main groups was supplemented by the variant module "CrossFit" developed by us. According to the results of researches obtained after the introduction of the experimental technique into the educational process for physical education, it was determined that in schoolchildren of the main groups, the level of development of power abilities increased from below average to above average. Changes weren't found on the score scale in the test control groups. In the age aspect, there is mainly an improvement in results with age, both in the main and control groups $(p>0,05)$. In the gender aspect, it was revealed, mainly, the reliable primacy of the data of boys over the indicators of girls $(p<0,05-0,001)$. Conclusions: significant positive changes were revealed in the indicators of the level of the strength development of the 10th-11th-grade pupils of the main groups, after using the experimental technique proposed by us in the educational process on physical education.

Keywords: variable module, CrossFit, high school pupils, power, physical culture lessons, motor activity.

\section{References}

1. Bala, T. M., Masliak, I. P. (2014), «The dynamics of the development level of speed under the influence of cheerleading exercises», Visnyk Chernihivskoho natsionalnoho pedahohichnoho universytetu. Ser.: pedahohichni nauky. Fizychne vykhovannia ta sport, №118 (3), pp. 14-17. http://nbuv.gov.ua/UJRN/VchdpuPN_2014_118(3)_5. (in Ukr.).

2. Holenkova, Yu. V., Halkina, A. V. (2015), «The development of coordination abilities of senior school girls by means of rhythmic gymnastics», Teoriia ta metodyka fizychnoho vykhovannia, №04, pp. 39-44. DOI: 10.17309/tmfv.2015.4.1155. (in Ukr.).

3. Horbunov, L. (2016), «The impact of health tourism on the level of physical preparedness of high school pupils», Fizychne vykhovannia, sport i kultura zdorovia u suchasnomu suspilstvi: zbirnyk naukovykh prats, №2 (10), pp. 47-49. https://sport.vnu.edu.ua/ index.php/sport/article/view/1098. (in Ukr.).

4. Kravchuk, T. M., Holivets, K. M. (2015), «Features of the use of dance exercises in the physical education of high school pupils», Teoriia ta metodyka fizychnoho vykhovannia, №4, pp. 11-16. http://nbuv.gov.ua/UJRN/TMFV_2015_4_3. (in Ukr.).

5. Kravchuk, T. M., Karpunets, T. V., Stepanenko, I. V. (2019), «Functional training as a means of developing strength abilities of high school pupils», Tekhnolohii zberezhennia zdorovia, reabilitatsiia i fizychna terapiia: zb. st. XII Mizhnar. nauk. konf., Kharkiv, pp. 132-136. (in Ukr.).

6. Krendelieva, V. U. (2015), «The impact of recreational fitness on the level of physical preparedness of high school pupils», Molodyi vchenyi, №3 (18), pp. 175-178. (in Ukr.).

7. Kuramshin, lu. F. (2010), Teoriia i metodika fizicheskoi kultury [The theory and methods of physical culture]. Moskva: Sovetskii sport, 320 p. (in Russ.).

8. Masliak, I. P. (2017), «The influence of power aerobics on state of the cardiorespiratory system of high school pupils», Naukovyi chasopys NPU imeni M. P. Drahomanova, №1 (82), pp. 35-38. http://enpuir.npu.edu.ua/handle/123456789/20398. (in Ukr.).

9. Masliak, I. P., Mameshyna, M. A., Zhuk, V. O. (2014), «State of using the innovative approaches in physical education of regional secondary schools», Slobozhanskyi naukovo-sportyvnyi visnyk, №6 (44), pp. 69-72. http://nbuv.gov.ua/UJRN/snsv 2014 6 15. (in Ukr.).

10. Petrova, A. S. (2021), "The influence of CrossFit exercises on the level of physical preparation of senior school pupils", Slobozhanskyi naukovo-sportyvnyi visnyk, №2 (82), pp. 63-69. DOI:10.15391/snsv.2021-2.010. (in Ukr.).

11. Romanenko, V. O. (2005), Diagnostika dvigatelnykh sposobnostei [Diagnostics of motor abilities]: ucheb. posobie. Donetck: DonNU, 290 p. (in Russ.).

12. Serhiienko, L. P. (2001), Testuvannia rukhovykh zdibnostei shkoliariv [Testing motor abilities of pupils]. Kyiv: Olimpiiska literatura, 439 p. (in Ukr.).

13. Skrypka, I. M., Cheridnichenko, S. V., Lysiak, M. O. (2018), «Introduction of the technique of strength training in the process of physical education of high school pupils», Naukovyi chasopys NPU imeni MP Drahomanova, №6 (100), pp. 74-77. (in Ukr.).

14. Suvorova, T. I., Moroz, M. S., Karabanov, A. H. (2011), «The impact of athletic gymnastics on the physical preparedness of high school pupils», Molodizhnyi naukovyi visnyk. Rozdil 1. Fizychna kultura, fizychne vykhovannia riznykh hrup naselennia, №6, pp. 13-16. (in Ukr.).

15. Sulyma, A. S., Nasalskyi, M. D., Fedorchuk, V. I. (2019), «The influence of sectional football classes on physical preparation of 11-12-year-old pupils», Fizychna reabilitatsiia ta rekreatsiino-ozdorovchi tekhnolohii, №1, pp. 20-24. (in Ukr.).

16. Fizychna kultura v shkoli (2019): navchalna prohrama dlia 10-11 klasiv zakladiv zahalnoi serednoi osvity [Physical culture in school : curriculum for 10-11 grades of general secondary education]. Kyiv: Litera LTD, 192 p. (in Ukr.).

17. Shamardina, H. M. (2007), Osnovy teorii ta metodyky fizychnoho vykhovannia [Fundamentals of the theory and methods of physical education]. Dnipropetrovsk: Driant, 486 p. (in Ukr.).

18. Shyian, B. M. (2009), Teoriia i metodyka fizychnoho vykhovannia shkoliariv [The theory and methods of physical education of pupils]: pidruchnyk: u 2-kh ch., Ternopil: Navchalna knyha-Bohdan, Ch.1, 272 p. (in Ukr.).

19. Galimova, A., Kudryavtsev, M., Galimov, G., Osipov, A., Astaf'ev, N., Zhavner, T., et al. (2018), «Increase in power striking characteristics via intensive functional training in CrossFit», Journal of Physical Education and Sport, Vol. 18 (2), pp. 585-591. DOI:10.7752/jpes.2018.02085. (in Eng.).

20. Masliak, I., Bala, T., Krivoruchko, N., Shesterova, L., Kuzmenko, I., Kulyk, N., Stasyuk, R., Zhuk, V. (2018), «Functional state of cardiovascular system of 10-16-year old teenagers under the influence of cheerleading classe», Journal of Physical Education and Sport, 18 Supplement, Issue 1, Art 63, pp. 452-458. DOI:10.7752/jpes.2018.s163. (in Eng.).

21. Kolomiitseva, O., Prykhodko, I., Prikhodko, A., Anatskyi, R., Turchynov, A., Fushev, S., Hunbina, S., Garkavyi, O. (2020), «Efficiency of Physical Education of University Students Based on the Motivation Choice of the CrossFit Program», Physical Activity Review, Vol. 8, pp. 26-38. (in Eng.).

22. Mulyk, K. V., Mulyk, V. V. (2015), «Motivation of schoolchildren and students for health related tourism», Pedagogics, psychology, medical-biological problems of physical training and sports, №7 (19), pp. 33-38. http://dx.doi.org/10.15561/18189172.2 015.0705. (in Eng.).

Петрова, А., Бала, Т. (2021), «Динаміка показників рівня розвитку сили школярів старших класів під впливом вправ кросфіту»
Слобожанський науково-спортивний вісник, № 6(86), С. 50-56, doi:10.15391/snsv.2021-6.008 
23. Sibley, B. A. (2012), «Using Sport Education to Implement a CrossFit Unit», Journal of Physical Education, Recreation \& Dance, Vol. 83 (8), pp. 42-48. DOI:10.1080/07303084.2012.10598829. (in Eng.).

24. Smith, M. M., Sommer, A. J., Starkoff, B. E., Devor, S. T. (2013), «Crossfit-based high-intensity power training improves maximal aerobic fitness and body composition», Journal of Strength and Conditioning Research, Vol. 27 (11), pp. 3159-3172. DOI:10.1519/JSC.0b013e318289e59f. (in Eng.).

Received: 16.11.2021.

Published: 23.12.2021.

\section{Відомості про авторів / Information about the Authors}

Петрова Ангеліна Сергіївна: доктор філософії (Ph.D); Харківська державна академія фізичної культури: вул. Клочківська 99, Харків, 61058, Україна.

Петрова Ангелина Сергеевна: доктор философии (Ph.D); Харьковская государственная академия физической культуры: ул. Клочковская, 99, г. Харьков, 61058, Украина.

Anhelina Petrova: doctor of philosophy (Ph.D); Kharkiv State Academy of Physical Culture: Klochkivska str. 99, Kharkiv, 61058, Ukraine.

ORCID: http://orcid.org/0000-0001-6400-8624

E-mail: petrovaangelina@ukr.net

Бала Тетяна Михайлівна: к. фіз.вих., доцент; Харківська державна академія фізичної культури: вул. Клочківська 99, Харків, 61058, Україна.

Бала Татьяна Михайловна: к. физ.восп., доцент; Харьковская государственная академія физической культуры: ул. Клочковская, 99, Харьков, 61058, Украина.

Tetiana Bala: PhD (Physical Education and Sport), Associate Professor; Kharkiv State Academy of Physical Culture: Klochkivska str. 99, Kharkiv, 61058, Ukraine. ORCID: http://orcid.org/0000-0002-5427-6796

E-mail: tanya.bala2206@gmail.com 